\title{
On the Wiener Polynomials of Some Trees
}

Ali A. Ali

aliazizali1933@yahoo.com
Ahmed M. Ali

ahmedgraph@uomosul.edu.iq

College of Computer Sciences and Mathematics

University of Mosul, Iraq

\section{Received on: 02/05/2006}

Accepted on: 16/08/2006

\section{ABSTRACT}

The Wiener index is a graphical invariant which has found many applications in chemistry. The Wiener Polynomial of a connected graph $\mathrm{G}$ is the generating function of the sequence $(C(G, k))$ whose derivative at $x=1$ is the Wiener index $W(G)$ of $G$, in which $C(G, k)$ is the number of pairs of vertices distance $\mathrm{k}$ apart. The Wiener Polynomials of star-like trees and other special trees are found in this paper; and hence a formula of the Wiener index for each such trees is obtained .

Keywords: Wiener Polynomials, Trees.

$$
\begin{aligned}
& \text { متعددات حدود وينر لبعض الاشجار } \\
& \text { علي عزيز علي أحمد محمد علي } \\
& \text { كلية علوم الحاسبات واليراضيات، جامعة الموصل }
\end{aligned}
$$

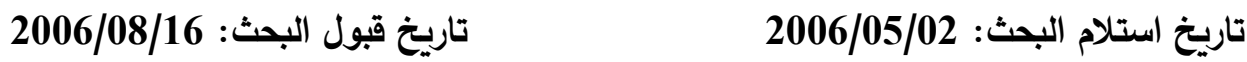

$$
\begin{aligned}
& \text { الملخص } \\
& \text { إنَّ دليل وينر هو لا متغير بياني أصبحت له تطبيقات عديدة في الكيمياء. ومتعددة حدود }
\end{aligned}
$$

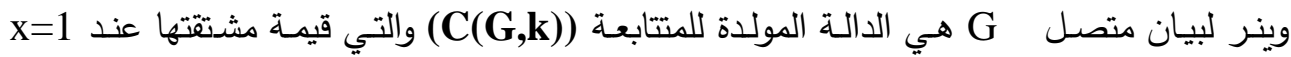

$$
\begin{aligned}
& \text { تساوي دليل وينر W(G للبيان G(G,k) ، إذ إن أن لهو عدد أزواج الرؤوس التي لكل منها المسافة }
\end{aligned}
$$

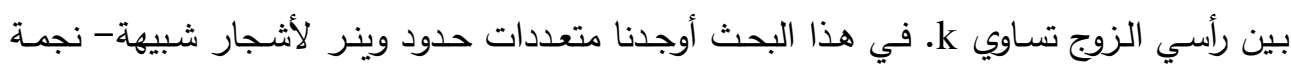

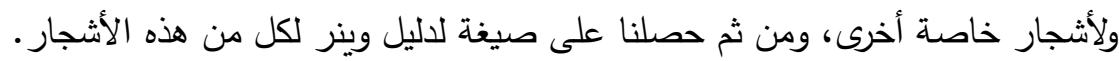

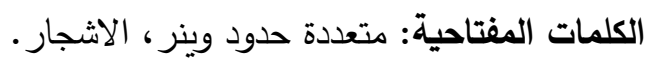

\section{Introduction}

Let $\mathrm{G}$ be a finite connected graph of vertex set $\mathrm{V}$. The distance between vertices $u$ and $v$ in $G$ is the length of a shortest $u-v$ path.

Let $\mathrm{d}_{\mathrm{G}}(\mathrm{u}, \mathrm{v})$, or simply $\mathrm{d}(\mathrm{u}, \mathrm{v})$, denote the distance between vertices $u$ and $v$. The eccentricity $e(v)$ of a vertex $v$ is the greatest possible distance from $v$ to all other vertices of $G$, that is 


$$
e(v)=\max _{u \in V} d(u, v) \text {. }
$$

The diameter of $\mathrm{G}$, denoted by diamG or $\delta$, is defined as

$$
\delta=\max _{\mathrm{v} \in \mathrm{V}} \mathrm{e}(\mathrm{v}) \text {. }
$$

The radius of $\mathrm{G}$, denoted by radG or $\mathrm{r}$, is defined as

$$
\mathrm{r}=\min _{\mathrm{v} \in \mathrm{V}} \mathrm{e}(\mathrm{v}) \text {. }
$$

The Wiener index of $\mathrm{G}$ is defined as

$$
\mathrm{W}(\mathrm{G})=\sum_{\{\mathrm{u}, \mathrm{v}\}} \mathrm{d}(\mathrm{u}, \mathrm{v}),
$$

where the sum is over all unordered pairs $\{\mathrm{u}, \mathrm{v}\}$ of distinct vertices in G. It is clear that

$$
\mathrm{W}(\mathrm{G})=\sum_{\mathrm{v} \in \mathrm{V}} \sigma(\mathrm{v}) / 2,
$$

where $\sigma(\mathrm{v})$ is the transmission of a vertex $\mathrm{v}$ defined by

$$
\sigma(\mathrm{v})=\sum_{\mathrm{u} \in \mathrm{V}} \mathrm{d}(\mathrm{v}, \mathrm{u}) \cdot
$$

The average distance of $\mathrm{G}$ is defined as

$$
\overline{\mathrm{D}}(\mathrm{G})=\mathrm{W}(\mathrm{G}) / \frac{1}{2} \mathrm{p}(\mathrm{p}-1)
$$

where $\mathrm{p}$ is the order of $\mathrm{G}$. It is know [2] that

$$
1 \leq \overline{\mathrm{D}}(\mathrm{G}) \leq \frac{1}{3}(\mathrm{p}+1)
$$

If $\mathrm{x}$ is a parameter, then the Wiener polynomial of $\mathrm{G}$ is

$$
\mathrm{W}(\mathrm{G} ; \mathrm{x})=\sum_{\{\mathrm{u}, \mathrm{v}\}} \mathrm{x}^{\mathrm{d}(\mathrm{u}, \mathrm{v})},
$$

where the sum is taken over all unordered pairs $\{u, v\}$ of vertices in $G$.

Let $\mathrm{d}(\mathrm{G}, \mathrm{k})$ denote the number of all distinguishable unordered pairs of vertices that are of distance $\mathrm{k}$ apart. Then

$$
\mathrm{W}(\mathrm{G} ; \mathrm{x})=\sum_{\mathrm{k}=0}^{\delta} \mathrm{d}(\mathrm{G}, \mathrm{k}) \mathrm{x}^{\mathrm{k}} \text {. }
$$

It is clear that the Wiener index $\mathrm{W}(\mathrm{G})$ is equal to the value of the derivative of $\mathrm{W}(\mathrm{G} ; \mathrm{x})$, with respect to $\mathrm{x}$, at $\mathrm{x}=1$

Deriving a formula for the Wiener polynomial of some type of graphs requires that the graphs must have a particular degree of uniformity. Therefore several authors had obtained Wiener polynomials for special 
graphs and compound graphs (see [4] and [5]).The trees are considered as the most important and useful kind of graphs.

Therefore many papers have been written about the average distance of particular graphs including trees. Since Wiener polynomials provide us with more information about distance, it is useful to find Wiener polynomials of some type of trees. In 1996, Sagan, Yeh and Zhang [6] obtained and studied Wiener polynomial for trees called "dendrimer" which are used in chemistry. In 2002, D. Bonchev and D. J. Klein [1] obtained the Wiener index of thorn rods and thorn stars that are used in theoretical chemistry. Therefore it is suitable to find Wiener polynomials for some other kinds of trees, as we have done in this paper.

\section{The Wiener Polynomial of a Star-like Tree}

Definition 2.1: A tree $\mathrm{T}$ of order $\mathrm{p} \geq 4$ is said to be a star-like tree if $\mathrm{T}$ is homomorphic with a star $\mathrm{F}$, i.e. it is possible to get $\mathrm{T}$ from $\mathrm{F}$ by inserting vertices of degree 2 on some edges of $\mathrm{F}$. The tree $\mathrm{T}$ has a particular root $\mathrm{c}$ which is in the origin the center of the star F. Let $\mathrm{u}_{1}, \mathrm{u}_{2}, \ldots, \mathrm{u}_{\mathrm{m}}$ be the endvertices of $\mathrm{T}$, and let, be the length of the unique path from $1 \leq \mathrm{i} \leq \mathrm{m}, \alpha_{\mathrm{i}}$ $c$ to $\mathrm{u}_{\mathrm{i}}$. Assume that the end-vertices of $\mathrm{T}$ are labeled such that $\alpha_{1} \leq \alpha_{2} \leq \ldots \leq \alpha_{m}$, then such star-like tree will be denoted by $\mathrm{T}\left(\alpha_{1}, \alpha_{2}, \ldots, \alpha_{\mathrm{m}}\right)$.

Now we find the Wiener Polynomial for $\mathrm{T}\left(\alpha_{1}, \alpha_{2}, \ldots, \alpha_{\mathrm{m}}\right)$, using the symbol [n] defined by

$$
[\mathrm{n}]=1+\mathrm{x}+\mathrm{x}^{2}+\ldots+\mathrm{x}^{\mathrm{n}-1},
$$

for every positive integer $n$.

Theorem 2.1: For any star-like tree $\mathrm{T}\left(\alpha_{1}, \alpha_{2}, \ldots, \alpha_{\mathrm{m}}\right)$ of order $\mathrm{p} \geq 4$, we have

$$
\begin{gathered}
\mathrm{W}\left(\left(\mathrm{T}, \alpha_{1}, \alpha_{2}, \ldots, \alpha_{\mathrm{m}}\right) ; \mathrm{x}\right)=\sum_{\mathrm{j}=1}^{\mathrm{m}}\left\{\sum_{\mathrm{i}=0}^{\alpha_{\mathrm{j}}}\left(\alpha_{\mathrm{j}}-\mathrm{i}\right) \mathrm{x}^{\mathrm{i}}\right\}+\left[1+\alpha_{1}\right]\left[1+\alpha_{2}\right] \\
+\sum_{\mathrm{r}=3}^{\mathrm{m}}\left(\left[1+\alpha_{1}\right]+\left[1+\alpha_{2}\right]+\ldots+\left[1+\alpha_{\mathrm{r}-1}\right]-\mathrm{r}+2\right)\left(\left[1+\alpha_{\mathrm{r}}\right]-1\right)
\end{gathered}
$$

\section{Proof:}


To simplify the symbols in this proof, we shall denote $\mathrm{T}_{(\mathrm{m})}$ for the starlike tree $T\left(\alpha_{1}, \alpha_{2}, \ldots, \alpha_{m}\right)$.

It is clear that the order of $T_{(m)}$ is $p=\alpha_{1}+\alpha_{2}+\ldots+\alpha_{m}+1$.

If $\mathrm{m}=1$, then $\mathrm{T}_{(1)}$ is a path from the vertex $\mathrm{c}$ to the vertex $\mathrm{u}_{1}$, and of the degree $1+\alpha_{1}$, and using the formula of the polynomial of a path [4], we get $\mathrm{W}\left(\mathrm{T}_{(1)} ; \mathrm{x}\right)=\sum_{\mathrm{i}=0}^{\alpha_{1}}\left(1+\alpha_{1}-\mathrm{i}\right) \mathrm{x}^{\mathrm{i}}$.

which is the same result obtained from (2.1) when $\mathrm{m}=1$.

If $m=2$, we use Theorem 1 of Gutman [4], and we get

$\mathrm{W}\left(\mathrm{T}_{(2)} ; \mathrm{x}\right)=\mathrm{W}\left(\mathrm{T}_{(1)} ; \mathrm{x}\right)+\mathrm{W}(\mathrm{F} ; \mathrm{x})+\mathrm{W}\left(\mathrm{c}, \mathrm{T}_{(1)} ; \mathrm{x}\right) \mathrm{W}(\mathrm{c}, \mathrm{F} ; \mathrm{x})$

$$
-\mathrm{W}\left(\mathrm{c}, \mathrm{T}_{(1)} ; \mathrm{x}\right)-\mathrm{W}(\mathrm{c}, \mathrm{F} ; \mathrm{x}) \text {, }
$$

where $\mathrm{F}$ is a path from the vertex $\mathrm{c}$ to the vertex $\mathrm{u}_{2}$ of order $1+\alpha_{2}$, and $\mathrm{T}_{(2)}=\mathrm{T}_{(1)} \bullet \mathrm{F}$.Hence we have

$$
\begin{aligned}
\mathrm{W}\left(\mathrm{T}_{(2)} ; \mathrm{x}\right) & =\sum_{\mathrm{i}=0}^{\alpha_{1}}\left(1+\alpha_{1}-\mathrm{i}\right) \mathrm{x}^{\mathrm{i}}+\sum_{\mathrm{i}=0}^{\alpha_{2}}\left(1+\alpha_{2}-\mathrm{i}\right) \mathrm{x}^{\mathrm{i}}+\left(\sum_{\mathrm{i}=0}^{\alpha_{1}} \mathrm{x}^{\mathrm{i}}\right)\left(\sum_{\mathrm{i}=0}^{\alpha_{2}} \mathrm{x}^{\mathrm{i}}\right) \\
& -\sum_{\mathrm{i}=0}^{\alpha_{1}} \mathrm{x}^{\mathrm{i}}-\sum_{\mathrm{i}=0}^{\alpha_{2}} \mathrm{x}^{\mathrm{i}} \\
= & \sum_{\mathrm{j}=1}^{2}\left\{\sum_{\mathrm{i}=0}^{\alpha_{\mathrm{j}}}\left(\alpha_{\mathrm{j}}-\mathrm{i}\right) \mathrm{x}^{\mathrm{i}}\right\}+\left[1+\alpha_{1}\right]\left[1+\alpha_{2}\right],
\end{aligned}
$$

which is the result obtained from (2.1) when we put $\mathrm{m}=2$.

If $m=3$ we a gain use Theorem 1 of Gutman [4], and we get

$\mathrm{W}\left(\mathrm{T}_{(3)} ; \mathrm{x}\right)=\mathrm{W}\left(\mathrm{T}_{(2)} ; \mathrm{x}\right)+\mathrm{W}(\mathrm{Q} ; \mathrm{x})+\mathrm{W}\left(\mathrm{c}, \mathrm{T}_{(2)} ; \mathrm{x}\right) \mathrm{W}(\mathrm{c}, \mathrm{Q} ; \mathrm{x})$

$$
-\mathrm{W}\left(\mathrm{c}, \mathrm{T}_{(2)} ; \mathrm{x}\right)-\mathrm{W}(\mathrm{c}, \mathrm{Q} ; \mathrm{x}) \text {, }
$$

where $Q$ is a path from the vertex $c$ to the vertex $u_{3}$ of order $1+\alpha_{3}$, and $\mathrm{T}_{(3)}=\mathrm{T}_{(2)} \bullet \mathrm{Q}$.Hence, we have

$$
\begin{aligned}
& \mathrm{W}\left(\mathrm{T}_{(3)} ; \mathrm{x}\right)=\mathrm{W}\left(\mathrm{T}_{(2)} ; \mathrm{x}\right)+\mathrm{W}(\mathrm{Q} ; \mathrm{x})-\mathrm{W}(\mathrm{c}, \mathrm{Q} ; \mathrm{x}) \\
& +\mathrm{W}\left(\mathrm{c}, \mathrm{T}_{(2)} ; \mathrm{x}\right)(\mathrm{W}(\mathrm{c}, \mathrm{Q} ; \mathrm{x})-1) \\
& \mathrm{W}\left(\mathrm{T}_{(3)} ; \mathrm{x}\right)=\sum_{\mathrm{j}=1}^{3}\left\{\sum_{\mathrm{i}=0}^{\alpha_{i}}\left(\alpha_{\mathrm{j}}-\mathrm{i}\right) \mathrm{x}^{\mathrm{i}}\right\}+\left[1+\alpha_{1}\right]\left[1+\alpha_{2}\right]
\end{aligned}
$$




$$
+\left(\left[1+\alpha_{1}\right]+\left[1+\alpha_{2}\right]-1\right)\left(\left[1+\alpha_{3}\right]-1\right),
$$

which is the result obtained from (2.1) when we put $\mathrm{m}=3$.

Now assume that the formula (2.1) be true for the tree $\mathrm{T}_{(\mathrm{k})}$, where $3 \leq \mathrm{k} \leq \mathrm{m}$.

We shall prove that it's true for the tree $\mathrm{T}_{(\mathrm{k}+1)}$.

Using Theorem (1) of Gutman [4], we get

$$
\begin{gathered}
\mathrm{W}\left(\mathrm{T}_{(\mathrm{k}+1)} ; \mathrm{x}\right)=\mathrm{W}\left(\mathrm{T}_{(\mathrm{k})} ; \mathrm{x}\right)+\mathrm{W}(\mathrm{R} ; \mathrm{x})+\mathrm{W}\left(\mathrm{c}, \mathrm{T}_{(\mathrm{k})} ; \mathrm{x}\right) \mathrm{W}(\mathrm{c}, \mathrm{R} ; \mathrm{x}) \\
-\mathrm{W}\left(\mathrm{c}, \mathrm{T}_{(\mathrm{k})} ; \mathrm{x}\right)-\mathrm{W}(\mathrm{c}, \mathrm{R} ; \mathrm{x})
\end{gathered}
$$

where $\mathrm{R}$ is a path from the vertex $\mathrm{c}$ to the vertex $\mathrm{u}_{\mathrm{k}+1}$ of order $1+\alpha_{\mathrm{k}+1}$, and that $\mathrm{T}_{(\mathrm{k}+1)}=\mathrm{T}_{(\mathrm{k})} \bullet \mathrm{R}$.

Then

$$
\begin{gathered}
\mathrm{W}\left(\mathrm{T}_{(\mathrm{k}+1)} ; \mathrm{x}\right)=\mathrm{W}\left(\mathrm{T}_{(\mathrm{k})} ; \mathrm{x}\right)+\mathrm{W}(\mathrm{R} ; \mathrm{x})-\mathrm{W}(\mathrm{c}, \mathrm{R} ; \mathrm{x}) \\
+\mathrm{W}\left(\mathrm{c}, \mathrm{T}_{(\mathrm{k})} ; \mathrm{x}\right)(\mathrm{W}(\mathrm{c}, \mathrm{R} ; \mathrm{x})-1) .
\end{gathered}
$$

It's clear that

$$
\begin{aligned}
\mathrm{W}\left(\mathrm{c}, \mathrm{T}_{(\mathrm{k})} ; \mathrm{x}\right) & =\sum_{\mathrm{i}=0}^{\alpha_{1}} \mathrm{x}^{\mathrm{i}}+\sum_{\mathrm{i}=1}^{\alpha_{2}} \mathrm{x}^{\mathrm{i}}+\ldots+\sum_{\mathrm{i}=1}^{\alpha_{k}} \mathrm{x}^{\mathrm{i}} \\
& =\left[1+\alpha_{1}\right]+\left[1+\alpha_{2}\right]+\ldots+\left[1+\alpha_{\mathrm{k}}\right]-(\mathrm{k}-1) .
\end{aligned}
$$

Therefore, substituting for, $\mathrm{W}\left(\mathrm{T}_{(\mathrm{k})} ; \mathrm{x}\right)$ and $\mathrm{W}\left(\mathrm{c}, \mathrm{T}_{(\mathrm{k})} ; \mathrm{x}\right)$ and simplify, we get

$$
\begin{aligned}
\mathrm{W}\left(\mathrm{T}_{(\mathrm{k}+1)} ; \mathrm{x}\right) & =\sum_{\mathrm{j}=1}^{\mathrm{k}+1}\left\{\sum_{\mathrm{i}=0}^{\alpha_{i}}\left(\alpha_{\mathrm{j}}-\mathrm{i}\right) \mathrm{x}^{\mathrm{i}}\right\}+\left[1+\alpha_{1}\right]\left[1+\alpha_{2}\right] \\
& +\sum_{\mathrm{r}=3}^{\mathrm{k}}\left(\left[1+\alpha_{1}\right]+\left[1+\alpha_{2}\right]+\ldots+\left[1+\alpha_{\mathrm{r}-1}\right]-\mathrm{r}+2\right)\left(\left[1+\alpha_{\mathrm{r}}\right]-1\right) \\
+\left(\left[1+\alpha_{1}\right]\right. & \left.+\left[1+\alpha_{2}\right]+\ldots+\left[1+\alpha_{\mathrm{k}}\right]-\mathrm{k}+1\right)\left(\left[1+\alpha_{\mathrm{k}+1}\right]-1\right) \\
= & \sum_{\mathrm{j}=1}^{\mathrm{k}+1}\left\{\sum_{\mathrm{i}=0}^{\alpha_{j}}\left(\alpha_{\mathrm{j}}-\mathrm{i}\right) \mathrm{x}^{\mathrm{i}}\right\}+\left[1+\alpha_{1}\right]\left[1+\alpha_{2}\right] \\
& +\sum_{\mathrm{r}=3}^{\mathrm{k}+1}\left(\left[1+\alpha_{1}\right]+\left[1+\alpha_{2}\right]+\ldots+\left[1+\alpha_{\mathrm{r}-1}\right]-\mathrm{r}+2\right)\left(\left[1+\alpha_{\mathrm{r}}\right]-1\right)
\end{aligned}
$$


Since the theorem is true for $\mathrm{T}_{(\mathrm{k}+1)}$, then it's true for any tree $\mathrm{T}_{(\mathrm{m})}$, and thus the proof is completed.

Corollary 2.2: Let $\mathrm{T}\left(\alpha_{1}, \alpha_{2}, \ldots, \alpha_{\mathrm{m}}\right)$ be a star-like tree of order $\mathrm{p} \geq 4$, where $\alpha_{1} \leq \alpha_{2} \leq \ldots \leq \alpha_{m}$, then its Wiener index is

$$
\begin{gathered}
\mathrm{W}\left(\left(\mathrm{T}, \alpha_{1}, \alpha_{2}, \ldots, \alpha_{\mathrm{m}}\right)\right)=\frac{1}{6} \sum_{\mathrm{j}=1}^{\mathrm{m}} \alpha_{\mathrm{j}}\left(\alpha_{\mathrm{j}}^{2}-1\right)+\frac{1}{2}\left(1+\alpha_{1}\right)\left(1+\alpha_{2}\right)\left(\alpha_{1}+\alpha_{2}\right) \\
+\frac{1}{2} \sum_{\mathrm{r}=3}^{\mathrm{m}} \alpha_{\mathrm{r}}\left\{\sum_{\mathrm{i}=1}^{\mathrm{r}-1}\left(1+\alpha_{\mathrm{i}}\right)^{2}+\alpha_{\mathrm{r}}\left(1+\sum_{\mathrm{i}=1}^{\mathrm{r}-1} \alpha_{\mathrm{i}}\right)-\mathrm{r}+2\right\}
\end{gathered}
$$

\section{Proof:}

Differentiating (2.1) with respect to $\mathrm{x}$ and replacing $\mathrm{x}=1$, we get

$$
\begin{aligned}
& \mathrm{W}\left(\left(\mathrm{T}, \alpha_{1}, \alpha_{2}, \ldots, \alpha_{\mathrm{m}}\right)\right)=\sum_{\mathrm{j}=1}^{\mathrm{m}}\left\{\sum_{\mathrm{i}=1}^{\alpha_{\mathrm{j}}} \mathrm{i}\left(\alpha_{\mathrm{j}}-\mathrm{i}\right)\right\}+\left(1+\alpha_{1}\right) \sum_{\mathrm{i}=1}^{\alpha_{2}} \mathrm{i}+\left(1+\alpha_{2}\right) \sum_{\mathrm{i}=1}^{\alpha_{1}} \mathrm{i} \\
&+ \sum_{\mathrm{r}=3}^{\mathrm{m}}\left\{\left(1+\alpha_{1}+\alpha_{2}+\ldots+\alpha_{\mathrm{r}-1}\right) \sum_{\mathrm{i}=1}^{\alpha_{\mathrm{r}}} \mathrm{i}\right\}+\sum_{\mathrm{r}=3}^{\mathrm{m}}\left\{\alpha_{\mathrm{r}}\left(\sum_{\mathrm{i}=1}^{\alpha_{1}} \mathrm{i}+\sum_{\mathrm{i}=1}^{\alpha_{2}} \mathrm{i}+\ldots+\sum_{\mathrm{i}=1}^{\alpha_{\mathrm{r}-1}} \mathrm{i}\right)\right\} \\
&= \sum_{\mathrm{j}=1}^{\mathrm{m}}\left\{\frac{1}{2} \alpha_{\mathrm{j}}^{2}\left(\alpha_{\mathrm{j}}+1\right)-\frac{1}{6} \alpha_{\mathrm{j}}\left(\alpha_{\mathrm{j}}+1\right)\left(2 \alpha_{\mathrm{j}}+1\right)\right\}+\frac{1}{2}\left(1+\alpha_{1}\right) \alpha_{2}\left(1+\alpha_{2}\right) \\
&+\frac{1}{2}\left(1+\alpha_{2}\right) \alpha_{1}\left(1+\alpha_{1}\right)+\frac{1}{2} \sum_{\mathrm{r}=3}^{\mathrm{m}} \alpha_{\mathrm{r}}\left\{\left(1+\sum_{\mathrm{i}=1}^{\mathrm{r}-1} \alpha_{\mathrm{i}}\right)\left(1+\alpha_{\mathrm{r}}\right)+\sum_{\mathrm{i}=1}^{\mathrm{r}-1} \alpha_{\mathrm{i}}\left(1+\alpha_{\mathrm{i}}\right)\right\} \\
&= \frac{1}{6} \sum_{\mathrm{j}=1}^{\mathrm{m}} \alpha_{\mathrm{j}}\left(\alpha_{\mathrm{j}}{ }^{2}-1\right)+\frac{1}{2}\left(1+\alpha_{1}\right)\left(1+\alpha_{2}\right)\left(\alpha_{1}+\alpha_{2}\right) \\
&+\frac{1}{2} \sum_{\mathrm{r}=3}^{\mathrm{m}} \alpha_{\mathrm{r}}\left\{\alpha_{\mathrm{r}}\left(1+\sum_{\mathrm{i}=1}^{\mathrm{r}-1} \alpha_{\mathrm{i}}\right)+1+2 \sum_{\mathrm{i}=1}^{\mathrm{r}-1} \alpha_{\mathrm{i}}+\sum_{\mathrm{i}=1}^{\mathrm{r}-1} \alpha_{\mathrm{i}}^{2}\right\} \\
&= \frac{1}{6} \sum_{\mathrm{j}=1}^{\mathrm{m}} \alpha_{\mathrm{j}}\left(\alpha_{\mathrm{j}}{ }^{2}-1\right)+\frac{1}{2}\left(1+\alpha_{1}\right)\left(1+\alpha_{2}\right)\left(\alpha_{1}+\alpha_{2}\right) \\
&+\frac{1}{2} \sum_{\mathrm{r}=3}^{\mathrm{m}} \alpha_{\mathrm{r}}\left\{\alpha_{\mathrm{r}}\left(1+\sum_{\mathrm{i}=1}^{\mathrm{r}-1} \alpha_{\mathrm{i}}\right)+\sum_{\mathrm{i}=1}^{\mathrm{r}-1}\left(1+\alpha_{\mathrm{i}}\right)^{2}-\mathrm{r}+2\right\} . \#
\end{aligned}
$$

Notice that it's possible to find the average distance of a star-like tree $\mathrm{T}\left(\alpha_{1}, \alpha_{2}, \ldots, \alpha_{\mathrm{m}}\right)$, by dividing the Wiener index $\mathrm{W}\left(\mathrm{T}\left(\alpha_{1}, \alpha_{2}, \ldots, \alpha_{\mathrm{m}}\right)\right)$ by $\left(\begin{array}{l}\mathrm{p} \\ 2\end{array}\right)$, where $\mathrm{p}=1+\sum_{\mathrm{i}=1}^{\mathrm{m}} \alpha_{\mathrm{i}}$. 
Definition 2.2: The tree $T\left(\alpha_{1}, \alpha_{2}, \ldots, \alpha_{m}\right)$ of order $\mathrm{p} \geq 4$ is called a $\underline{\text { Fan }}$ graph if $\alpha_{j}=\alpha, 1 \leq \mathrm{j} \leq \mathrm{m}$, which will be denoted by $\mathrm{F}(\mathrm{m}, \alpha)$.

Corollary 2.3: The Wiener Polynomial of a fan graph $\mathrm{F}(\mathrm{m}, \alpha)$ is given by

$\mathrm{W}(\mathrm{F}(\mathrm{m}, \alpha) ; \mathrm{x})=\mathrm{m} \sum_{\mathrm{i}=0}^{\alpha}(1+\alpha-\mathrm{i}) \mathrm{x}^{\mathrm{i}}+\frac{1}{2} \mathrm{~m}(\mathrm{~m}-1)([1+\alpha]-1)^{2}-\mathrm{m}+1$

\section{Proof:}

Using Theorem 2.1 and putting $\alpha_{j}=\alpha$ for all $\mathrm{j}=1,2, \ldots, \mathrm{m}$, we get

$$
\begin{aligned}
\mathrm{W}(\mathrm{F}(\mathrm{m}, \alpha) ; \mathrm{x}) & =\sum_{\mathrm{j}=1}^{\mathrm{m}}\left\{\sum_{\mathrm{i}=0}^{\alpha}(\alpha-\mathrm{i}) \mathrm{x}^{\mathrm{i}}\right\}+[1+\alpha]^{2} \\
& +\sum_{\mathrm{r}=3}^{\mathrm{m}}((\mathrm{r}-1)[1+\alpha]-\mathrm{r}+2)([1+\alpha]-1) \\
& =\mathrm{m} \sum_{\mathrm{i}=0}^{\alpha}(\alpha-\mathrm{i}) \mathrm{x}^{\mathrm{i}}+[1+\alpha]^{2}+[1+\alpha]^{2} \sum_{\mathrm{r}=3}^{\mathrm{m}}(\mathrm{r}-1) \\
& -[1+\alpha] \sum_{\mathrm{r}=3}^{\mathrm{m}}(2 \mathrm{r}-3)+\sum_{\mathrm{r}=3}^{\mathrm{m}}(\mathrm{r}-2) \\
& =\mathrm{m} \sum_{\mathrm{i}=0}^{\alpha}(\alpha-\mathrm{i}) \mathrm{x}^{\mathrm{i}}+\frac{1}{2} \mathrm{~m}(\mathrm{~m}-1)[1+\alpha]^{2}-\mathrm{m}(\mathrm{m}-2)[1+\alpha] \\
& +\frac{1}{2}(\mathrm{~m}-1)(\mathrm{m}-2) \\
& =\mathrm{m} \sum_{\mathrm{i}=0}^{\alpha}(1+\alpha-\mathrm{i}) \mathrm{x}^{\mathrm{i}}+\frac{1}{2} \mathrm{~m}(\mathrm{~m}-1)([1+\alpha]-1)^{2}-\mathrm{m}+1 .
\end{aligned}
$$

We notice that when $\alpha=1$, the fan $\mathrm{F}(\mathrm{m}, 1)$ becomes a star of order $\mathrm{m}+1$, and if we substitute $\alpha=1$ in the formula (2.2) we get the Wiener Polynomial of the star of order $m+1$.

Corollary 2.4: The Wiener index of a fan graph $F(m, \alpha)$ of order $p \geq 4$ is $\mathrm{W}\left(\mathrm{F}(\mathrm{m}, \alpha)=\frac{1}{6} \mathrm{~m} \alpha(1+\alpha)(3 \mathrm{~m} \alpha-2 \alpha+2)\right.$,

and its average distance is $\overline{\mathrm{D}}(\mathrm{F}(\mathrm{m}, \alpha))={ }_{(1+\alpha)}\left[1-\frac{2 \alpha+1}{3(\mathrm{~m} \alpha+1)}\right]$. 


\section{Proof:}

The Wiener index $\mathrm{W}(\mathrm{F}(\mathrm{m}, \alpha)$ follows from corollary 2.2 by substituting $\alpha_{j}=\alpha$ for $j=1,2, \ldots, m$.

And since the number of vertices of $F(m, \alpha)$ is $p=m \alpha+1$, then its average distance is

$$
\begin{aligned}
\overline{\mathrm{D}}(\mathrm{F}(\mathrm{m}, \alpha)) & =\frac{2}{(\mathrm{~m} \alpha+1) \mathrm{m} \alpha} \mathrm{W}(\mathrm{F}(\mathrm{m}, \alpha)) \\
= & \frac{(1+\alpha)(3 \mathrm{~m} \alpha-2 \alpha+2)}{3(\mathrm{~m} \alpha+1)}=(1+\alpha)\left[1-\frac{2 \alpha+1}{3(\mathrm{~m} \alpha+1)}\right] .
\end{aligned}
$$

Its clear from the above result that $\overline{\mathrm{D}}(\mathrm{F}(\mathrm{m}, \alpha))<1+\alpha$, and this inequality generally means that the average distance of the tree $\mathrm{F}(\mathrm{m}, \alpha)$ is bounded above by $1+\mathrm{e}(\mathrm{c})$, where $\mathrm{c}$ is root .

\section{Other trees}

Definition 3.1: Let $M_{a(\alpha), b(\beta), \gamma}$ be a tree constructed from a path whose vertices ( in order ) are $\mathrm{w}_{1}, \mathrm{w}_{2}, \ldots, \mathrm{w}_{\gamma}$ with a fan graph $\mathrm{F}(\mathrm{a}, \alpha)$ which has $\mathrm{w}_{\gamma}$ as its center, and another fan graph $\mathrm{F}(\mathrm{b}, \beta)$ of center $\mathrm{w}_{1}$, as shown in Fig. 3.1.
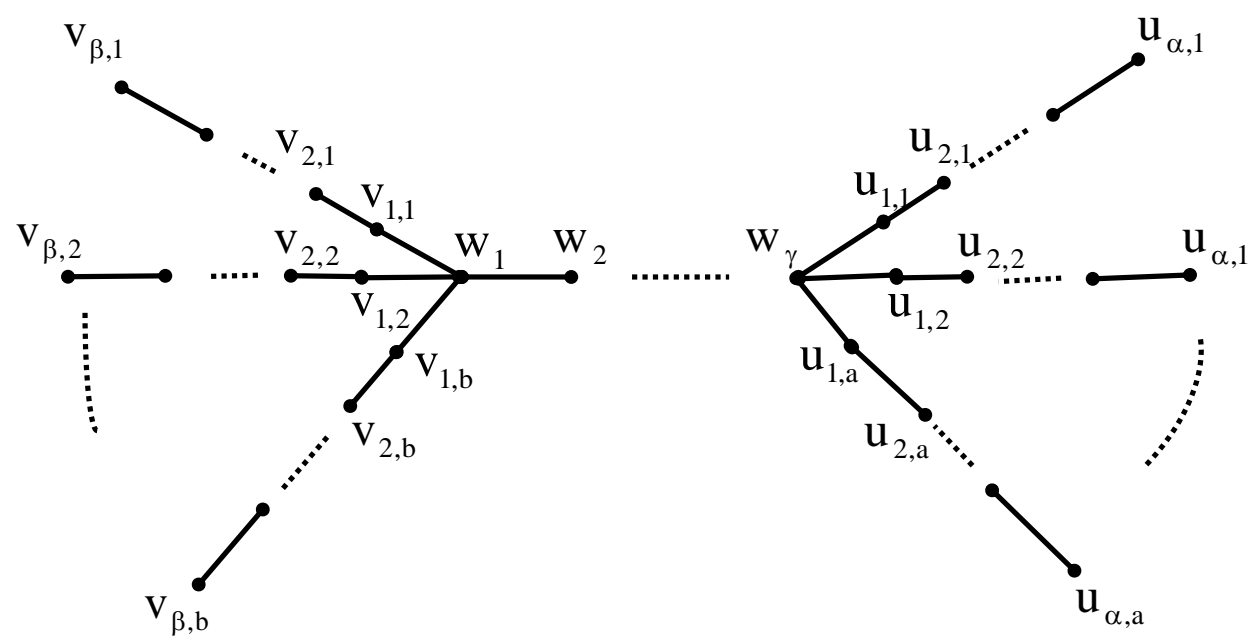
Fig. 3.1,. The tree $M_{a(\alpha), b(\beta), \gamma}$

Notice that the order of $\mathrm{M}_{\mathrm{a}(\alpha), \mathrm{b}(\beta), \gamma}$ is $\mathrm{p}=\mathrm{a} \alpha+\mathrm{b} \beta+\gamma$, its diameter $\alpha+\beta+\gamma-1$, and will suppose that $\gamma \geq \alpha \geq \beta$.

To simplify the symbol $\mathbf{M}_{\mathrm{a}(\alpha), \mathrm{b}(\beta), \gamma}$ we'll denote it by $\mathrm{M}$ in the following results.

Theorem 3.1: The Wiener Polynomial of a tree $M$ is given by $W(M ; x)=\sum_{k=0}^{\delta} d(M, k) x^{k}$, where $d(M, 0)=p=a \alpha+b \beta+\gamma$, and for all $k \geq 1$, we have

$$
\mathrm{d}(\mathrm{M}, \mathrm{k})=\left[\begin{array}{c}
\mathrm{p}-\mathrm{k}+(\mathrm{k}-1)\left\{\left(\begin{array}{l}
\mathrm{a} \\
2
\end{array}\right)+\left(\begin{array}{l}
\mathrm{b} \\
2
\end{array}\right)\right\} ; \text { when } 1 \leq \mathrm{k} \leq \beta \\
\mathrm{p}-\mathrm{k}+(\mathrm{k}-1)\left(\begin{array}{l}
\mathrm{a} \\
2
\end{array}\right)+\left(\begin{array}{c}
2 \beta+1-\mathrm{k} \\
1
\end{array}\right)\left(\begin{array}{l}
\mathrm{b} \\
2
\end{array}\right) ; \text { when } \beta<\mathrm{k} \leq \alpha \\
\mathrm{p}-\mathrm{k}+\left(\begin{array}{c}
2 \alpha+1-\mathrm{k} \\
1
\end{array}\right)\left(\begin{array}{l}
\mathrm{a} \\
2
\end{array}\right)+\left(\begin{array}{c}
2 \beta+1-\mathrm{k} \\
1
\end{array}\right)\left(\begin{array}{l}
\mathrm{b} \\
2
\end{array}\right) ; \text { when } \alpha<\mathrm{k} \leq \gamma \\
\mathrm{a}\left(\begin{array}{c}
\alpha+\gamma-\mathrm{k} \\
1
\end{array}\right)+\mathrm{b}\left(\begin{array}{c}
\beta+\gamma-\mathrm{k} \\
1
\end{array}\right)+\left(\begin{array}{c}
2 \alpha+1-\mathrm{k} \\
1
\end{array}\right)\left(\begin{array}{l}
\mathrm{a} \\
2
\end{array}\right) \\
+\left(\begin{array}{c}
2 \beta+1-\mathrm{k} \\
1
\end{array}\right)\left(\begin{array}{l}
\mathrm{b} \\
2
\end{array}\right)+\text { mab; when } \gamma<\mathrm{k} \leq \delta
\end{array}\right.
$$

in which

$$
\mathrm{m}=\left[\begin{array}{ll}
\mathrm{k}-\gamma ; & \text { when } \gamma<\mathrm{k} \leq \gamma+\beta-1 \\
-\beta ; & \text { when } \gamma+\beta \leq \mathrm{k} \leq \gamma+\alpha \\
\delta-\mathrm{k}+1 ; & \text { when } \gamma+\alpha+1 \leq \mathrm{k} \leq \delta
\end{array}\right.
$$


and $\delta=\alpha+\beta+\gamma-1$

Proof:

We partition the set of the vertices of the tree $\mathrm{M}$ into three subsets $V_{1}, V_{2}, V_{3}$, where

$\mathrm{V}_{1}=\left\{\mathrm{w}_{1}, \mathrm{w}_{2}, \ldots, \mathrm{w}_{\gamma}\right\}$,

$\mathrm{V}_{2}=\bigcup_{\mathrm{i}=1}^{\mathrm{a}} \mathrm{V}_{2 \mathrm{i}}, \mathrm{V}_{2 \mathrm{i}}=\left\{\mathrm{u}_{1, \mathrm{i}}, \mathrm{u}_{2, \mathrm{i}}, \ldots, \mathrm{u}_{\alpha, \mathrm{i}}\right\}, \quad 1 \leq \mathrm{i} \leq \mathrm{a}$,

$\mathrm{V}_{3}=\bigcup_{\mathrm{i}=1}^{\mathrm{b}} \mathrm{V}_{3 \mathrm{i}}, \mathrm{V}_{3 \mathrm{i}}=\left\{\mathrm{v}_{1, \mathrm{i}}, \mathrm{v}_{2, \mathrm{i}}, \ldots, \mathrm{v}_{\beta, \mathrm{i}}\right\}, \quad 1 \leq \mathrm{i} \leq \mathrm{b}$,

It's clear that each of the induced sub graphs $\left\langle V_{2 i}>\right.$ and, is a $\left\langle V_{3 i}>\right.$ path.

To explain the proof we divide it into two parts.

First: When $1 \leq \mathrm{k} \leq \gamma$, this part is divided into the following three cases (a) When $1 \leq \mathrm{k} \leq \beta$, we note that

1. If the two vertices were in the set $\mathrm{V}_{2 \mathrm{i}}$, or if one of the two vertices is in the set $\mathrm{V}_{2 \mathrm{i}}$ and the other vertex is in the set $\mathrm{V}_{1}$, for all $1 \leq \mathrm{i} \leq \mathrm{a}$, then we have $\alpha$, of the pairs that are distance $\mathrm{k}$ apart, and this case leads to $a \alpha$ unordered pairs for all these values of $i$.

2. If the two vertices were in the set $\mathrm{V}_{3 \mathrm{i}}$, or if one of the two vertices is in the set $\mathrm{V}_{3 \mathrm{i}}$ and the other vertex is in the set $\mathrm{V}_{1}$, for all $1 \leq \mathrm{i} \leq \mathrm{b}$, then we have $\beta$, of the pairs that are distance $\mathrm{k}$ apart, and this case leads to $b \beta$ unordered pairs for all these values of $i$.

3. If the two vertices are in the set $V_{1}$, then we have $\gamma-k$ pairs .

4. If one of the two vertices was in the set $\mathrm{V}_{2 \mathrm{i}}$ and the other was in the set $\mathrm{V}_{2 \mathrm{j}}$ for each $\mathrm{i} \neq \mathrm{j}$, then we have $(\mathrm{k}-1)$ unordered pairs, and this leads to $(\mathrm{k}-1)\left(\begin{array}{l}\mathrm{a} \\ 2\end{array}\right)$ when we take all the cases for $\mathrm{i}, \mathrm{j}=1,2, \ldots, \mathrm{a}$. 
Similarly, we have $(\mathrm{k}-1)\left(\begin{array}{l}\mathrm{b} \\ 2\end{array}\right)$ unordered pairs if one of the two vertices is in the set $\mathrm{V}_{3 \mathrm{i}}$ and the other is in the set $\mathrm{V}_{3 \mathrm{j}}$ for each $\mathrm{i} \neq \mathrm{j}$, and for all values of $i, j=1,2, \ldots, b$.

Hence, the total number of unordered pairs of vertices that are distance $\mathrm{k}$ apart, when $1 \leq \mathrm{k} \leq \beta$ is

$\mathrm{a} \alpha+\mathrm{b} \beta+\gamma-\mathrm{k}+(\mathrm{k}-1)\left(\begin{array}{l}\mathrm{a} \\ 2\end{array}\right)+(\mathrm{k}-1)\left(\begin{array}{l}\mathrm{b} \\ 2\end{array}\right)$.

Therefore

$\mathrm{d}(\mathrm{M}, \mathrm{k})=\mathrm{p}-\mathrm{k}+(\mathrm{k}-1)+\left\{\left(\begin{array}{l}\mathrm{a} \\ 2\end{array}\right)+\left(\begin{array}{l}\mathrm{b} \\ 2\end{array}\right)\right\} ; \quad$ when $1 \leq \mathrm{k} \leq \beta$

(b) When $\beta<\mathrm{k} \leq \alpha$, then the numbers of unordered pairs of vertices mentioned in case (a) are all hold except for the case in which one of the two vertices is in the set $\mathrm{V}_{3 \mathrm{i}}$ and other is in $\mathrm{V}_{3 \mathrm{j}}$ for all $\mathrm{i} \neq \mathrm{j}$, in which if, $\mathrm{k} \leq 2 \beta$, then the number of the pairs is $2 \beta+1-\mathrm{k}$, and if $\mathrm{k}>2 \beta$, the number of the pairs is zero. Therefore

$\mathrm{d}(\mathrm{M}, \mathrm{k})=\mathrm{p}-\mathrm{k}+(\mathrm{k}-1)\left(\begin{array}{l}\mathrm{a} \\ 2\end{array}\right)+\left(\begin{array}{c}2 \beta+1-\mathrm{k} \\ 1\end{array}\right)\left(\begin{array}{l}\mathrm{b} \\ 2\end{array}\right)$, when $\beta<\mathrm{k} \leq \alpha$.

Notice that its not true in this case to write the number $\left(\begin{array}{c}2 \beta+1-\mathrm{k} \\ 1\end{array}\right)$ in the form $2 \beta+1-\mathrm{k}$, since, if $\mathrm{k} \geq 2 \beta+1$, then this combination will be zero, this style of expression will be used later in similar cases.

(c) When $\alpha<\mathrm{k} \leq \gamma$, then the numbers of unordered pairs of vertices mentioned in case (b) are all hold all except for the case in which one of the two vertices is in the set $\mathrm{V}_{2 \mathrm{i}}$ and other is in $\mathrm{V}_{2 \mathrm{j}}$ for all $\mathrm{i} \neq \mathrm{j}$, in which if, $\mathrm{k} \leq 2 \alpha$, the number of the pairs is $2 \alpha+1-\mathrm{k}$, and if $\mathrm{k}>2 \alpha$, the number of the pairs is zero. Therefore $\mathrm{d}(\mathrm{M}, \mathrm{k})=\mathrm{p}-\mathrm{k}+\left(\begin{array}{c}2 \alpha+1-\mathrm{k} \\ 1\end{array}\right)\left(\begin{array}{l}\mathrm{a} \\ 2\end{array}\right)+\left(\begin{array}{c}2 \beta+1-\mathrm{k} \\ 1\end{array}\right)\left(\begin{array}{l}\mathrm{b} \\ 2\end{array}\right), \quad$ when $\alpha<\mathrm{k} \leq \gamma$.

Second: When, the unordered pairs of vertices that are distance k apart are of the following five kinds: 
(1) One vertex in the set $V_{1}$ and the other in the set $V_{2}$; the number of the these pairs is

$\mathrm{a}\left(\begin{array}{c}\alpha+\gamma-\mathrm{k} \\ 1\end{array}\right)$.

(2) One vertex in the set $V_{1}$ and the other in the set $V_{3}$; the number of the these pairs is

$\mathrm{b}\left(\begin{array}{c}\beta+\gamma-\mathrm{k} \\ 1\end{array}\right)$.

(3) One vertex in the set $V_{2 i}$ and the other in the set $V_{2 j}$; for all $i \neq j$; the total number of these pairs is

$\left(\begin{array}{l}\mathrm{a} \\ 2\end{array}\right)\left(\begin{array}{c}2 \alpha+1-\mathrm{k} \\ 1\end{array}\right)$.

(4) One vertex in the set $V_{3 i}$ and the other in the set $V_{3 j}$; for all $i \neq j$; the total number of these pairs is

$\left(\begin{array}{l}b \\ 2\end{array}\right)\left(\begin{array}{c}2 \beta+1-k \\ 1\end{array}\right)$.

(5) One vertex in the set $V_{2}$ and the other in the set $V_{3}$ (i.e. a vertex in $V_{2 i}$ and other in $\mathrm{V}_{3 \mathrm{j}}$ ) where $1 \leq \mathrm{i} \leq \mathrm{a}, 1 \leq \mathrm{j} \leq \mathrm{b}$, then the number of such pairs of vertices is mab in which the values of $m$ depend on $k$, and we find it easily from Fig. 3.2.
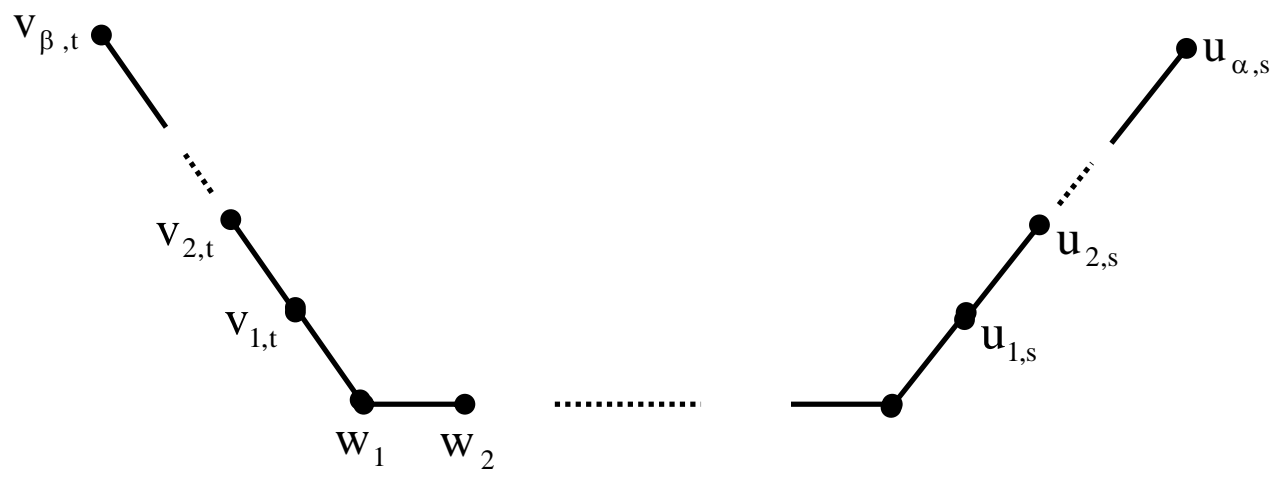

Fig.3.2 
Therefore if $\gamma<\mathrm{k} \leq \gamma+\beta-1$, then $\mathrm{m}=\mathrm{k}-\gamma$;

if $\gamma+\beta \leq \mathrm{k} \leq \gamma+\alpha$, then $\mathrm{m}=\beta$;

if $\gamma+\alpha<\mathrm{k} \leq \delta$, then $\mathrm{m}=\delta+1-\mathrm{k}$.

Hence by taking the numbers of pairs in the cases (1),(2),(3),(4) and (5), we get the formula mentioned in the statement of the theorem when $\gamma<\mathrm{k} \leq \delta$. Thus the proof is completed .

\section{Remark}

The Wiener Polynomial of the tree $\mathbf{M}_{\mathrm{a}(\alpha), \mathrm{b}(\beta), \gamma}$ can be expressed in the terms of Wiener Polynomial of the path graph $Q=\left\langle V_{1}\right\rangle$, the fan graph $\mathrm{F}(\mathrm{b}, \beta)$, and the fan graph $\mathrm{F}(\mathrm{a}, \alpha)$, by using Theorem (1) of Gutman [4], as it is given in the next theorem.

Theorem 3.1: For the tree $(\mathrm{M}=)=\mathrm{M}_{\mathrm{a}(\alpha), \mathrm{b}(\beta), \gamma}$ we have

$$
\begin{aligned}
& \mathrm{W}(\mathrm{M} ; \mathrm{x})=\mathrm{W}(\mathrm{Q} ; \mathrm{x})+\mathrm{W}(\mathrm{F}(\mathrm{b}, \beta) ; \mathrm{x})+\mathrm{W}(\mathrm{F}(\mathrm{a}, \alpha) ; \mathrm{x})-2 \\
& +\mathrm{b}\left(\sum_{\mathrm{k}=1}^{\beta} \mathrm{x}^{\mathrm{k}}\right)\left(\sum_{\mathrm{k}=1}^{\gamma-1} \mathrm{x}^{\mathrm{k}}\right) \\
& \quad+\mathrm{a}\left(\sum_{\mathrm{k}=1}^{\alpha} \mathrm{x}^{\mathrm{k}}\right)\left(\sum_{\mathrm{k}=1}^{\gamma-1} \mathrm{x}^{\mathrm{k}}+\mathrm{b} \sum_{\mathrm{k}=\mathrm{\gamma}}^{\gamma+\beta-1} \mathrm{x}^{\mathrm{k}}\right)
\end{aligned}
$$

\section{Proof:}

Let $\mathrm{H}=\mathrm{Q} \bullet \mathrm{F}(\mathrm{b}, \beta)$, then

$\mathrm{W}(\mathrm{H} ; \mathrm{x})=\mathrm{W}(\mathrm{Q} ; \mathrm{x})+\mathrm{W}(\mathrm{F}(\mathrm{b}, \beta) ; \mathrm{x})+\left\{\mathrm{W}\left(\mathrm{w}_{1}, \mathrm{Q} ; \mathrm{x}\right)-1\right\}\left\{\mathrm{W}\left(\mathrm{w}_{1}, \mathrm{~F}(\mathrm{~b}, \beta) ; \mathrm{x}\right)-1\right\}-1$

$=\mathrm{W}(\mathrm{Q} ; \mathrm{x})+\mathrm{W}(\mathrm{F}(\mathrm{b}, \beta) ; \mathrm{x}))+\mathrm{b}\left(\sum_{\mathrm{k}=1}^{\beta} \mathrm{x}^{\mathrm{k}}\right)\left(\sum_{\mathrm{k}=1}^{\gamma-1} \mathrm{x}^{\mathrm{k}}\right)-1$

Since $M=H \bullet F(a, \alpha)$, then

$$
\begin{aligned}
\mathrm{W}(\mathrm{M} ; \mathrm{x}) & =\mathrm{W}(\mathrm{H} ; \mathrm{x})+\mathrm{W}(\mathrm{F}(\mathrm{a}, \alpha) ; \mathrm{x}) \\
& +\left\{\mathrm{W}\left(\mathrm{w}_{\gamma}, \mathrm{H} ; \mathrm{x}\right)-1\right\}\left\{\mathrm{W}\left(\mathrm{w}_{\gamma}, \mathrm{F}(\mathrm{a}, \alpha) ; \mathrm{x}\right)-1\right\}-1
\end{aligned}
$$

But

$$
\mathrm{W}\left(\mathrm{w}_{\gamma}, \mathrm{H} ; \mathrm{x}\right)=1+\sum_{\mathrm{k}=1}^{\gamma-1} \mathrm{x}^{\mathrm{k}}+\mathrm{b} \sum_{\mathrm{k}=\gamma}^{\gamma+\beta-1} \mathrm{x}^{\mathrm{k}}
$$

and $\mathrm{W}\left(\mathrm{w}_{\gamma}, \mathrm{F}(\mathrm{a}, \alpha) ; \mathrm{x}\right)=1+\mathrm{a} \sum_{\mathrm{k}=1}^{\alpha} \mathrm{x}^{\mathrm{k}}$ 
Thus, substituting (1),(3) and (4) in (2), we get the required relation (3.1).

Notice that Theorem 3.2 is more general than Theorem 3.1, because it doesn't require the condition $\gamma \geq \alpha \geq \beta$; but it's possible to find formulas for $\mathrm{d}(\mathrm{M}, \mathrm{k})$ when $\alpha \geq \gamma \geq \beta$ or $\alpha \geq \beta \geq \gamma$, as in Theorem 3.1.

But Theorem 3.1 is more useful than Theorem 3.2 when we want to find the coefficient of a particular power of $\mathrm{x}$.

Corollary 3.3: The Wiener index of the tree $\mathrm{M}=\mathrm{M}_{\mathrm{a}(\alpha), \mathrm{b}(\beta), \gamma}$ is

$$
\begin{aligned}
\mathrm{W}(\mathrm{M}) & =\frac{1}{6}\left\{\gamma\left(\gamma^{2}-1\right)+\mathrm{b}(3 \mathrm{~b}-2) \beta^{3}+\mathrm{a}(3 \mathrm{a}-2) \alpha^{3}+(\mathrm{a} \alpha+\mathrm{b} \beta)\left(3 \gamma^{2}-1\right)\right\} \\
& +\frac{1}{2}\left\{\mathrm{~b}(\mathrm{~b}-1) \beta^{2}+\mathrm{a}(\mathrm{a}-1) \alpha^{2}+\mathrm{b}(\mathrm{a} \alpha+\gamma) \beta^{2}+\mathrm{a}(\mathrm{b} \beta+\gamma) \alpha^{2}\right\}+\mathrm{ab} \alpha \beta \gamma .
\end{aligned}
$$

\section{Proof:}

To get the Wiener index of $\mathbf{M}_{\mathrm{a}(\alpha), \mathrm{b}(\beta), \gamma}$, differentiate the formula

(3.1) with respect to $\mathrm{x}$ then substitute $\mathrm{x}=1$, as follows:

$$
\begin{aligned}
\mathrm{W}(\mathrm{M} ; \mathrm{x}) & =\mathrm{W}^{\prime}(\mathrm{M}, 1)=\mathrm{W}(\mathrm{Q})+\mathrm{W}(\mathrm{F}(\mathrm{b}, \beta))+\mathrm{W}(\mathrm{F}(\mathrm{a}, \alpha)) \\
+ & \mathrm{b} \beta \sum_{\mathrm{k}=1}^{\gamma-1} \mathrm{k}+\mathrm{b}(\gamma-1) \sum_{\mathrm{k}=1}^{\beta} \mathrm{k}+\mathrm{a} \alpha\left(\sum_{\mathrm{k}=1}^{\gamma-1} \mathrm{k}+\mathrm{b} \sum_{\mathrm{k}=\gamma}^{\gamma+\beta-1} \mathrm{k}\right)+\mathrm{a}(\gamma-1+\mathrm{b} \beta) \sum_{\mathrm{k}=1}^{\alpha} \mathrm{k} \\
= & \frac{1}{6} \gamma\left(\gamma^{2}-1\right)+\frac{1}{6} \mathrm{~b} \beta(1+\beta)(3 \mathrm{~b} \beta-2 \beta+2) \\
+ & \frac{1}{6} \mathrm{a} \alpha(1+\alpha)(3 \mathrm{a} \alpha-2 \alpha+2)+\frac{1}{2} \mathrm{~b} \beta \gamma(\gamma-1)+\frac{1}{2} \mathrm{~b}(\gamma-1) \beta(\beta+1) \\
+ & \mathrm{a} \alpha\left\{\frac{1}{2} \gamma(\gamma-1)+\mathrm{b}\left(\gamma \beta+\frac{1}{2} \beta(\beta-1)\right)\right\}+\frac{1}{2} \mathrm{a}(\gamma-1+\mathrm{b} \beta) \alpha(\alpha+1)
\end{aligned}
$$

Simplifying the above expression, we get

$$
\begin{aligned}
\mathrm{W}(\mathrm{M}) & =\frac{1}{6}\left\{\gamma\left(\gamma^{2}-1\right)+\mathrm{b}(3 \mathrm{~b}-2) \beta^{3}+\mathrm{a}(3 \mathrm{a}-2) \alpha^{3}+(\mathrm{a} \alpha+\mathrm{b} \beta)\left(3 \gamma^{2}-1\right)\right\} \\
& +\frac{1}{2}\left\{\mathrm{~b}(\mathrm{~b}-1) \beta^{2}+\mathrm{a}(\mathrm{a}-1) \alpha^{2}+\mathrm{b}(\mathrm{a} \alpha+\gamma) \beta^{2}+\mathrm{a}(\mathrm{b} \beta+\gamma) \alpha^{2}\right\}+a b \alpha \beta \gamma
\end{aligned}
$$




\section{REFERENCES}

[1] Bonchev, D. and D. J. Klein (2002) "On the Wiener number of Thorn Trees, Stars, Rings and Rods", Croatica chemica ACTA; CCACAA, Vol. 75, No.2, PP.613-620.

[2] Buckley, F. and F. Harary (1990) Distance in Graphs. Addison - Wesley, New York.

[3] Doyle, J.K. and J.E. Graver (1977) "Mean distance in a graph", Discrete Math., Vol. 17, PP.147-154.

[4] Gutman, I. (1993) Some properties of the Wiener polynomial ; Graph Theory Notes of New York; XXV. The New York Academy of Sciences, PP.13-17.

[5] Saeed, W. A.M. (1999) "Wiener Polynomials of Graphs", Ph.D. Thesis, Moul University.

[6] Sagan, B.E.; Y.N. Yeh and P. Zhang (1996) "The wiener polynomial of a graphs", International J. Qutman Chem.60, No.5, 959-969. 